\title{
Fatal pulmonary aspiration during balanced sedation with dexmedetomidine and midazolam - A case report -
}

Received June 26, 2018

Revised September 1, 2018

Accepted September 17, 2018

\section{Corresponding author}

Min A Kwon, M.D., Ph.D.

Department of Anesthesiology and Pain Medicine, Dankook University Hospital, 201 Manghyang-ro, Dongnam-gu, Cheonan 31116, Korea

Tel: 82-41-550-6814

Fax: 82-41-550-3918

E-mail: mmauss73@gmail.com ORCID

https://orcid.org/0000-0002-7253-3768

\section{Jeong Heon Park, Sang Yun Kim, and Min A Kwon}

Department of Anesthesiology and Pain Medicine, Dankook University Hospital, Cheonan, Korea

Recently, balanced sedation has commonly been used during procedural sedation. Dexmedetomidine is known for its relative safety to cause "conscious sedation" with little respiratory depression but has some limitations such as frequent awakening and hemodynamic instability during surgery. To facilitate sedation, a small dose of midazolam can be co-administered rather than escalating the dose of dexmedetomidine, especially in elderly patient. Despite the respiratory safety profile of dexmedetomidine, the overall safety of co-administration has not been clarified. We describe the first case of fatal pulmonary aspiration that developed in an elderly patient during balanced sedation with spinal anesthesia for elective femur fracture surgery.

Keywords: Conscious sedation; Dexmedetomidine; Respiratory aspiration of gastric contents.
An ideal sedative should have a fast onset and offset of drug efficacy, be predictable and titratable, and have no serious side effects. Additionally, low price burden is preferable.

Dexmedetomidine is a selective $\alpha 2$-adrenergic receptor agonist and is known to be a safe sedative that causes little respiratory depression [1]. It is characterized by "conscious sedation" and a clean and easy arousal from sedation, similar to being awakened by natural sleep [2]. Despite its expanded use within variable populations for procedural sedation, life-threatening pulmonary aspiration associated with dexmedetomidine has rarely been reported in cases of procedural sedation [3]. However, dexmedetomidine has some disadvantages, such as slower onset, frequent in-procedural awakenings, hemodynamic instability, and longer stay in postoperative care units $[4,5]$. Recently, "balanced sedation" has been introduced as an alternative strategy to increased doses of dexmedetomidine. Some sedatives or opioids such as ketamine, midazolam, or other opioids (e.g., remifentanil infusion) can be co-administered. However, the coadministration of other drugs can not guarantee the complete safety $[6,7]$.

We describe a case of fatal pulmonary aspiration that developed in balanced sedation with dexmedetomidine and a small amount of midazolam during spinal anesthesia in an elderly patient.

\section{CASE REPORT}

The patient was an 84-year-old male $(155 \mathrm{~cm}$ in height and $52 \mathrm{~kg}$ in weight) with a history of hypertension and kyphoscoliosis. He was transferred to our trauma center because of periprosthetic fracture of the left hip. He had undergone hip hemiarthroplasty 4 years ago and again fractured at the same position. He had cane-assisted ambulation prior to surgery and was relatively healthy for his age. Following routine preoperative examinations, including laboratory investigations,

This is an Open Access article distributed under the terms of the Creative Commons Attribution Non-Commercial License (http://creativecommons.org/licenses/by-nc/4.0) which permits unrestricted non-commercial use, distribution, and reproduction in any medium, provided the original work is properly cited. 
the patient was scheduled for elective revision hip hemiarthroplasty. He was alert and not delirious. He was not hypotensive or hypoxemic. Spinal anesthesia with adequate sedation was planned to proceed in consideration of an old age. The patient had adequately fasted from the midnight before the surgery.

In the morning on the day of surgery, the patient took his medication for hypertension. Upon arrival to the operating room, his oxygen saturation $\left(\mathrm{SpO}_{2}\right)$ was $93-95 \%$, blood pressure (BP) was $110 / 75 \mathrm{mmHg}$ (within $20 \%$ of baseline in the ward), and body temperature was $36.9^{\circ} \mathrm{C}$. Invasive arterial pressure was continuously monitored via right radial artery cannulation. Partial pressure of oxygen $\left(\mathrm{PaO}_{2}\right)$ at room air was $69 \mathrm{mmHg}$. The patient was placed in the lateral decubitus position, and spinal anesthesia was performed using $12 \mathrm{mg}$ of $0.5 \%$ hyperbaric bupivacaine and $20 \mu \mathrm{g}$ of fentanyl through L4/5. The level of anesthesia was checked T6, and 6 L of oxygen was supplied via a facial mask.

Sedation was initiated with $1 \mu \mathrm{g} / \mathrm{kg}$ of dexmedetomidine for $10 \mathrm{~min}$, followed by a $0.5-\mu \mathrm{g} / \mathrm{kg} / \mathrm{h}$ infusion. A bispectral index (BIS) monitor was placed on the left forehead and monitored throughout the surgery. He fell asleep $16 \mathrm{~min}$ after dexmedetomidine administration. During the loading dose, his BP dropped to $78 / 44 \mathrm{mmHg}$, and he exhibited bradycardia of 40-44 beats per min. He was administered $5 \mathrm{mg}$ of ephedrine and $100 \mu \mathrm{g}$ of phenylephrine.

Because of frequent hammering and handling throughout the surgery, the patient started to wake up often beginning 20 min after the start of the surgery. His BIS rose to $\geq 80$, and the dexmedetomidine dose was increased to $0.7 \mu \mathrm{g} / \mathrm{kg} / \mathrm{h}$. The surgery was highly complicated because of the revision approach. The estimated blood loss was approximately 1,200 ml. Two hours after anesthesia, the patient began to move because of uncomfortable posture and frequent awakening; however, he did not display signs of pain. Anesthetic team chose balanced sedation and concurrently administered 2 mg of midazolam, considering his hemodynamic vulnerability. The patient was finally moderately sedated and immobile. His BIS was within the range of 50-75, and self-respiration was regular. However, 15 min after midazolam administration, his $\mathrm{SpO}_{2}$ reduced to $88-92 \%$. He did not exhibit coughing, retching, or vomiting, but there was a small amount of gastric juice in his mouth. Further, his BP decreased to 88/44 mmHg. All sedatives were stopped, and we encouraged the patient to take a breath. The patient was not dyspneic and responded appropriately to our request. His $\mathrm{SpO}_{2}$ was maintained at 93-97\% with $10 \mathrm{~L}$ of oxygen via a facial mask. Dopamine was administered at $5-10 \mu \mathrm{g} / \mathrm{kg} / \mathrm{min}$ to restore BP. Given the patient's improper lateral positioning, the surgery was hastened. A chest X-ray in the operating room (Fig. 1) revealed diffuse infiltration, suggesting pulmonary aspiration in the right lung. For close monitoring and management, the patient was transferred to the intensive care unit (ICU) postoperatively. The duration of the surgery was $183 \mathrm{~min}$, and the duration of anesthesia was $238 \mathrm{~min}$.

After arrival at the ICU, the patient's BP was $127 / 88 \mathrm{mmHg}$ and heart rate 128 beats per min. Dopamine was administered at $10 \mu \mathrm{g} / \mathrm{kg} / \mathrm{min}$, and oxygen was supplied via a $6-\mathrm{L}$ facial mask. Arterial blood gas analysis revealed an $\mathrm{SpO}_{2}$ of $97 \%, \mathrm{PH}$ of $7.39, \mathrm{PaO}_{2}$ of $59 \mathrm{mmHg}$, partial pressure of $\mathrm{CO}_{2}$ of $41 \mathrm{mmHg}$, and a base excess of $-0.2 \mathrm{mM}$. The patient could say his name but could not correctly respond when asked
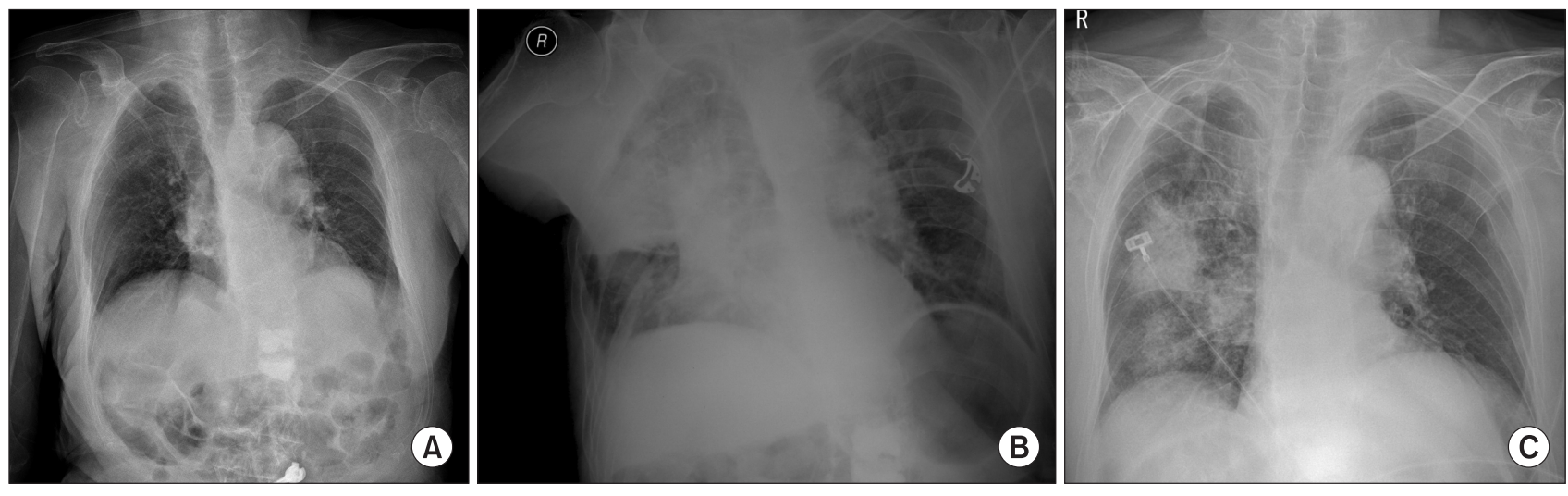

Fig. 1. Chest $X$ rays (A) preoperative, (B) intraoperative, and (C) postoperative. 
about the time and place.

Antibiotics were administered, and conservative lung treatment was given to the patient. In ICU, his BP gradually decreased and $\mathrm{SpO}_{2}$ did not improve. The patient became irritable and dyspneic. Norepinephrine was administered, and endotracheal intubation was performed.

There was no significant difference in chest $\mathrm{X}$-ray findings, and his body temperature was $37.5-38.0^{\circ} \mathrm{C}$. In the night on the surgery day, there was an episode of paroxysmal supraventricular tachycardia, and $6 \mathrm{mg}$ of adenosine was administered. His BP remained low, between 75 and $90 \mathrm{mmHg}$, despite the administration of $20 \mu \mathrm{g} / \mathrm{kg} / \mathrm{min}$ of dopamine and $0.3-6 \mu \mathrm{g} / \mathrm{kg} / \mathrm{min}$ of norepinephrine. The gastric acid-tinged copious secretions persisted in endotracheal suction, and $\mathrm{PaO}_{2}$ was maintained within $50-70 \mathrm{mmHg}$.

Despite the use of maximal doses of inotropes and supportive care, multiorgan failure progressed rapidly. He showed the signs of severe metabolic acidosis, increased creatinine levels, markedly increased hepatic enzyme levels, and persistent hypotension. The patient died on the night after the surgery.

\section{DISCUSSION}

We report a case of fatal pulmonary aspiration in balanced sedation with dexmedetomidine and a small amount of midazolam during spinal anesthesia of an elderly patient with a femur fracture undergoing revision hip hemiarthroplasty.

Although the postoperative outcomes associated with anesthetic methods in elderly patients undergoing hip fracture surgeries are a subject of ongoing debate, regional anesthesia is often preferred for its association with reduced postoperative complications and shortened hospital stays [8]. Elderly patients may not remain immobile long enough to allow a surgery to be completed; consequently, moderate to deep sedation is often required. The potential complications of deep sedation include hypoventilation, apnea, airway obstruction, aspiration, and hemodynamic instability [9]. For elderly patients, safer sedation strategies with lesser respiratory depression and stable hemodynamics are required [10].

We selected balanced sedation using a dexmedetomidine infusion with intermittent midazolam. Dexmedetomidine is a relatively new drug that has been widely used for procedural sedation. It is a selective $\alpha 2$-adrenergic receptor agonist ( $\alpha 2$ : $\alpha 1$ ratio of 1,620:1) that induces sedation and anxiolysis in a dose-dependent manner. Because central $\alpha 1$-adrenoceptor activation offsets the sedative $\alpha 2$-adrenergic effects, greater selectivity leads to greater sedation potency of the effect of the $\alpha 2$ receptor [11]. Dexmedetomidine has a unique sedation effect, similar to natural sleep, because of its effects on central pre- and postsynaptic $\alpha 2$ receptors in the locus coeruleus rather than through gamma-aminobutyric acid (GABA) receptors as with other drugs, such as propofol or midazolam [12]. This permits the patient to easily awaken to a lucid state and cooperate with instructions, referred to as "conscious sedation." [11].

Since first developed for use in patients receiving mechanical ventilation in 1999, the use of dexmedetomidine has been widely expanded to general anesthesia, postoperative sedation, and procedural sedation. Moreover, there have been various off-label applications ranging from pediatric to elderly patients, intranasal or buccal administration, coadministration of an adjuvant to local analgesia techniques, and balanced sedation with other sedatives or opioids [11]. Despite its respiratory safety, its safety in off-label use with elderly patients and co-administration with other medications has not been clarified [11].

The incidence of pulmonary aspiration during sedation is extremely rare and much lower than that of respiratory complications [3]. Pulmonary aspiration occurs when there is a loss of airway reflexes and elevated pressure in the stomach, sufficient to overcome the lower esophageal sphincter tone. Although several drugs, such as propofol and opioids, can reduce the lower esophageal sphincter tone [13], it is difficult to elevate the intragastric pressure to overcome the lower esophageal sphincter tone. This is because the stomach is very distensible and there is a very large reserve of volume till the intragastric pressure increases. In the usual setting of anesthesia or sedation without intestinal obstruction or insufficient mask ventilation, the development of significant pulmonary aspiration is uncommon [13].

Most cases of pulmonary aspiration reportedly develop during airway manipulation in the general anesthesia. Even in the procedural sedation, many cases of aspiration have been reported in the endoscopic procedure [3]. In nonendoscopic procedures, the incidence of aspiration was low and most patients recovered well. Only one case of nonendoscopic procedural sedation in an immunocompromised patient resulted in death [14]. Moreover, there has been no 
report of death associated with pulmonary aspiration with dexmedetomidine sedation [3].

In the present case, the patient maintained "conscious sedation" throughout the procedure; however, the addition of a small dose of midazolam to the dexmedetomidine infusion allowed the patient to attain a transient deep sedation state. Consequently, aspiration was possible due to the weakening of the protective airway reflex because of synergic effects on pharyngeal function [7]. Although the aspirated volume was small, it was more acidic than larger volumes and caused more severe and irreversible pulmonary sequelae [15].

Except old age and the use of sedatives, there were no such specific predisposing factors for pulmonary aspiration in this case. The patient had a full fasting time and no gastric obstruction, abnormal reflux, or stasis [3].

Considering the rapidly progressive clinical course, other possible causes that required differentiation included myocardial ischemia, stress-induced cardiomyopathy, or pulmonary embolism. However, the patient's risk of pulmonary embolism was small given that he only underwent 2 days of immobilization. Moreover, there were no apparent ischemic findings on electrocardiogram (EKG) or symptoms of chest pain. Further evaluations, such as computed tomography scans, were not performed given the patient's unstable hemodynamics.

Incidental pulmonary aspiration resulted in acute respiratory distress syndrome and pulmonary hypertension. Subsequent systemic hypoperfusion, severe metabolic acidosis, and multiorgan failure drove the patient into sudden collapse. The difficulties in maintaining oxygenation and perfusion pressure appear to have accelerated this deterioration. Applying extracorporeal membrane oxygenation (ECMO) may have been helpful but was not implemented because of family refusal [13].

This case is the first report of fatal pulmonary aspiration that developed in balanced sedation with dexmedetomidine and low-dose midazolam during spinal anesthesia. Keeping aside the perceived safety of the medication used and the duration of the presurgical fast, any procedural sedation with the possibility of losing consciousness can induce severe pulmonary aspiration. Care should be taken to select a sedation method that completely considers both risks and benefits. Furthermore, meticulous dose selection and the ability to immediately respond to adverse effects are essential, particu- larly in elderly or compromised patients.

\section{CONFLICTS OF INTEREST}

No potential conflict of interest relevant to this article was reported.

\section{ORCID}

Jeong Heon Park: https://orcid.org/0000-0003-3852-5390

Sang Yun Kim: https://orcid.org/0000-0001-8764-9942

\section{REFERENCES}

1. Boyd BC, Sutter SJ. Dexmedetomidine sedation for awake fiberoptic intubation of patients with difficult airways due to severe odontogenic cervicofacial infections. J Oral Maxillofac Surg 2011; 69: 1608-12.

2. Mahmoud M, Mason KP. Dexmedetomidine: review, update, and future considerations of paediatric perioperative and periprocedural applications and limitations. Br J Anaesth 2015; 115: 171-82.

3. Green SM, Mason KP, Krauss BS. Pulmonary aspiration during procedural sedation: a comprehensive systematic review. $\mathrm{Br} \mathrm{J}$ Anaesth 2017; 118: 344-54.

4. Sun Y, Lu Y, Huang Y, Jiang H. Is dexmedetomidine superior to midazolam as a premedication in children? A meta-analysis of randomized controlled trials. Paediatr Anaesth 2014; 24: 863-74.

5. Hong JY, Kim WO, Yoon Y, Choi Y, Kim SH, Kil HK. Effects of intravenous dexmedetomidine on low-dose bupivacaine spinal anaesthesia in elderly patients. Acta Anaesthesiol Scand 2012; 56: 382-7.

6. Tryba M. Choices in sedation: the balanced sedation technique. Eur J Anaesthesiol Suppl 1996; 13: 8-12.

7. Salonen M, Reid K, Maze M. Synergistic interaction between alpha 2-adrenergic agonists and benzodiazepines in rats. Anesthesiology 1992; 76: 1004-11.

8. Neuman MD, Rosenbaum PR, Ludwig JM, Zubizarreta JR, Silber $\mathrm{JH}$. Anesthesia technique, mortality, and length of stay after hip fracture surgery. JAMA 2014; 311: 2508-17.

9. Koroglu A, Demirbilek S, Teksan H, Sagir O, But AK, Ersoy MO. Sedative, haemodynamic and respiratory effects of dexmedetomidine in children undergoing magnetic resonance imaging examination: preliminary results. Br J Anaesth 2005; 94: 821-4.

10. Yeom JH, Ahn DW, Kim KH. Comparison of several dosing schedules of intravenous dexmedetomidine in elderly patients 
under spinal anesthesia. Anesth Pain Med 2017; 12: 320-5.

11. Weerink MAS, Struys MMRF, Hannivoort LN, Barends CRM, Absalom AR, Colin P. Clinical Pharmacokinetics and Pharmacodynamics of dexmedetomidine. Clin Pharmacokinet 2017; 56: 893913.

12. Bol CJ, Vogelaar JP, Tang JP, Mandema JW. Quantification of pharmacodynamic interactions between dexmedetomidine and midazolam in the rat. J Pharmacol Exp Ther 2000; 294: 347-55.
13. Nason KS. Acute intraoperative pulmonary aspiration. Thorac Surg Clin 2015; 25: 301-7.

14. Kelly CR, Ihunnah C, Fischer M, Khoruts A, Surawicz C, Afzali A, et al. Fecal microbiota transplant for treatment of Clostridium difficile infection in immunocompromised patients. Am J Gastroenterol 2014; 109: 1065-71.

15. Engelhardt T, Webster NR. Pulmonary aspiration of gastric contents in anaesthesia. Br J Anaesth 1999; 83: 453-60. 